\title{
Evaluating a simple blending approach to prepare magnetic and stimuli-responsive composite hydrogel particles for application in biomedical field
}

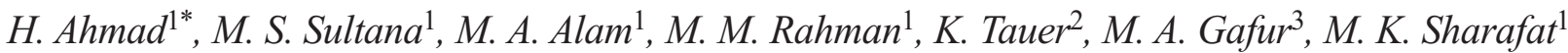 \\ ${ }^{1}$ Department of Chemistry, Rajshahi University, 6205 Rajshahi, Bangladesh \\ ${ }^{2}$ Max Planck Institute of Colloid and Interfaces, Am Mühlenberg, 14476 Golm, Germany \\ ${ }^{3}$ Pilot Plant and Process Development Centre, BCSIR, 1205 Dhaka, Bangladesh
}

Received 30 January 2016; accepted in revised form 1 March 2016

\begin{abstract}
The inclusion of super paramagnetic iron oxide $\left(\mathrm{Fe}_{3} \mathrm{O}_{4}\right)$ nanoparticles in stimuli-responsive hydrogel is expected to enhance the application potential for cellular therapy in cell labeling, separation and purification, protein immobilization, contrasting enhancement in magnetic resonance imaging (MRI), localized therapeutic hyperthermia, biosensors etc. in biomedical field. In this investigation two different magnetic and stimuli-responsive composite hydrogel particles with variable surface property were prepared by simply blending $\mathrm{Fe}_{3} \mathrm{O}_{4} / \mathrm{SiO}_{2}$ nanocomposite particles with stimuli-responsive hydrogel particles. Of the hydrogel particles prepared by free-radical precipitation polymerization poly(styrene-N-isopropylacrylamide-methyl methacrylate-polyethylene glycol methacrylate) or P(S-NIPAM-MMA-PEGMA) was temperature-sensitive and poly(S-NIPAM-methacrylic acid-PEGMA) or P(S-NIPAM-MAA-PEGMA) was both temperature- and pH-responsive. The morphological structure, size distributions and volume phase transitions of magnetic and stimuli-responsive composite hydrogel particles were analyzed. Temperature-responsive absorptions of biomolecules were observed on both magnetic and stimuli-responsive $\mathrm{Fe}_{3} \mathrm{O}_{4} / \mathrm{SiO}_{2} / \mathrm{P}\left(\mathrm{S}-\mathrm{NIPAM}-\mathrm{MMA}-\mathrm{PEGMA}\right.$ ) and $\mathrm{Fe}_{3} \mathrm{O}_{4} / \mathrm{SiO}_{2} / \mathrm{P}(\mathrm{S}-\mathrm{NIPAM}-\mathrm{MAA}-\mathrm{PEGMA}$ ) composite hydrogel particles and separation of particles from the dispersion media could be achieved by applying magnetic field without time consuming centrifugation or decantation method.
\end{abstract}

Keywords: smart polymers, stimuli-responsive hydrogel, magnetic nanocomposite, blending, magnetic composite hydrogel

\section{Introduction}

Stimuli-responsive hydrogels known as smart materials are macromolecules that undergo reversible volume phase transition in response to a small change of external stimuli such as temperature [1-9], $\mathrm{pH}$ [913], light [14-16], electric current [17-19], ionic strength [20-22] or chemical species [23]. Researchers are showing much attention in these materials for their wide range of biomedical and pharmaceutical applications [24-29]. However, temperature-sensitive hydrogels are the most studied class of stimuli-responsive polymers as they have strong application potential in pharmaceutical formulation. Poly(N-isopropylacrylamide) (PNIPAM) based temperature-responsive hydrogels have been extensively studied because their physicochemical properties can easily be tailored by insertion of other comonomers into the polymer chain, they exhibit low cytotoxicity and can be drained out from the organism [30, 31]. With the increase in temperature PNIPAM chains soluble in aqueous medium dehydrate at the temperature above the lower critical solution temperature (LCST) of $\sim 32^{\circ} \mathrm{C}$ as attractive segmental interactions among the hydrophobic isopropyl groups dominate. This in- 
duces a conformation change from a coil to globular state and turns the transparent PNIPAM solution into turbid emulsion.

The design of magnetic and stimuli-responsive composite hydrogel particles would be interesting because of wide application probability in magnetic bioseparation, drug delivery, magnetic resonance imaging contrast enhancement [32-39]. In magnetic and stimuli-responsive composite hydrogel particles, the first allows a suitable and energy efficient separation capability of biomolecule/drug loaded composite particles from the complex culture medium and the latter allows easy uptake and elution of absorbed biomolecule/drug. It is also plausible to assume that poor mechanical strength and flame-retardant property of hydrogel particles will be improved due to the inclusion of an inorganic component. These improved properties may offer additional advantage in industrial applications as well as in catalysis. In the literature several approaches are available for the preparation of magnetic composite polymer microspheres. Some works are available on the synthesis of magnetic hybrid composite particles based on the precipitation of magnetic $\left(\mathrm{Fe}_{3} \mathrm{O}_{4}\right)$ nanoparticles in bulk solution where polymer particles have been previously dispersed [7, 37, 40]. However for temperature-sensitive hydrogels, this process may affect the thermal response because high specific surface area of nanoparticles would favor interaction between nanoparticles and hydrogel matrix. Some authors cover the surface of the magnetic nanoparticles with $\mathrm{SiO}_{2}$ prior to the polymerization because surface of $\mathrm{Fe}_{3} \mathrm{O}_{4}$ nanoparticles inhibit polymerization [35, 41, 42]. Despite of this limitation, reports are available on direct precipitation polymerization of NIPAM and monomers in aqueous media using anionic initiator in the presence of stabilized iron oxide nanoparticles [43, 44]. Rahman and Elaissari [45] reported the preparation of divinylbenzene (DVB) cross-linked magnetic seed particles by emulsion polymerization of DVB while using potassium persulfate as initiator in the presence of native $\mathrm{Fe}_{3} \mathrm{O}_{4}$ emulsion followed by precipitation polymerization of NIPAM to induce temperature sensitive PNIPAM shell. Few are also available on the direct dispersion polymerization in ethanol/ water media $[46,47]$. In these methods the size of obtained microspheres often showed broad distribution. Other authors functionalized the surface of
$\mathrm{Fe}_{3} \mathrm{O}_{4}$ or $\mathrm{Fe}_{3} \mathrm{O}_{4} / \mathrm{SiO}_{2}$ nanoparticles with reactive vinyl group using silane coupling agent prior to the precipitation polymerization with NIPAM and/comonomers [35, 48-51]. Additionally grafting-to [52-54] and grafting-from $[38,54-56]$ approaches for the preparation of metal/metal oxide-polymer core-shell nanoparticles on iron oxide core, different polymerization methods such as atom transfer radical polymerization (ATRP) [54, 56, 57], nitroxide mediated polymerization (NMP) [56] and reversible addition-fragmentation transfer radical polymerization (RAFT) [53, $58]$ have been reported. All these processes require a tedious time consuming multistep procedure which often limit their applications. In a recently published article Illés et al. [59] discussed the preparation biocompatible carboxyl functional magnetic fluids consisting of core-shell PEG-acrylate-acrylic acid (PEGA-AA) comb-like copolymer by simple adsorption technique. Prior to this (PEGA-AA) was synthesized by quasiliving ATRP using a complex of $\mathrm{Cu}(\mathrm{I})$ chloride and hexamethyl-triethylene-tetramine as catalyst.

In the present research a simple economically feasible route is evaluated to prepare two different magnetic and stimuli-responsive nanocomposite hydrogel particles. In one series temperature-sensitive poly (styrene-NIPAM-methyl methacrylate-polyethylene glycol methacrylate) or P(S-NIPAM-MMA-PEGMA) hydrogel particles and in another series temperatureand $\mathrm{pH}$-responsive poly(S-NIPAM-methacrylic acidPEGMA) or P(S-NIPAM-MAA-PEGMA) hydrogel particles were prepared by free-radical precipitation copolymerization using cationic 2,2'-azobis(2amidinopropane)dihydrochloride (V-50) initiator. The weight ratio of styrene/MMA/PEGMA and styrene/ MAA/PEGMA in the recipe was optimized in order to produce stable emulsion and could not be maintained at the same ratio. Styrene was used as a hydrophobic comonomer avoiding the use of crosslinker. MMA/MAA was added to improve the solubility of styrene in the aqueous dispersion media for facilitating smooth copolymerization with NIPAM as the latter in absence of MMA/MAA may produce larger proportion of water soluble homopolymer due to its comparatively high reaction rate. The hydrophobichydrophobic interactions among hydrophobic PSPMMA or PS segments in the prepared conetworks are expected to form microgels in water, a phenom- 
enon generally observed for amphiphilic copolymer networks consisting of hydrophilic and hydrophobic polymer segments [60-64]. Then in one pot synthesis $\mathrm{Fe}_{3} \mathrm{O}_{4}$ nanoparticles were encapsulated with $\mathrm{SiO}_{2}$ to obtain $\mathrm{Fe}_{3} \mathrm{O}_{4} / \mathrm{SiO}_{2}$ nanocomposite particles and subsequently blended with hydrogel particles to obtain $\mathrm{Fe}_{3} \mathrm{O}_{4} / \mathrm{SiO}_{2} / \mathrm{P}(\mathrm{S}-\mathrm{NIPAM}-\mathrm{MMA}-\mathrm{PEGMA})$ and $\mathrm{Fe}_{3} \mathrm{O}_{4} /$ $\mathrm{SiO}_{2} / \mathrm{P}$ (S-NIPAM-MAA-PEGMA) composite hydrogel particles. The preparation scheme of these magnetic and stimuli-responsive composite hydrogel particles is shown in Figure 1. Under the preparation conditions $\mathrm{Fe}_{3} \mathrm{O}_{4} / \mathrm{SiO}_{2}$ nanocomposite particles are negatively charged due to the presence of silanol groups. Since the blending was carried out in presence of $\mathrm{NH}_{4} \mathrm{OH}$ solution with $\mathrm{pH}>10$, the $\mathrm{P}(\mathrm{S}$ NIPAM-MAA-PEGMA) hydrogel particles carried both positive and negative charges derived from initiator fragments and deprotonated carboxyl groups respectively. So the electrostatic attraction among $\mathrm{Fe}_{3} \mathrm{O}_{4} / \mathrm{SiO}_{2}$ nanocomposite particles and P(S-NIPAMMAA-PEGMA) hydrogel particles may be not that good for successful blending. Compared to this in the preparation of $\mathrm{Fe}_{3} \mathrm{O}_{4} / \mathrm{SiO}_{2} / \mathrm{P}$ (S-NIPAM-MMAPEGMA) composite hydrogel particles electrostatic attraction is expected to dominate among negatively charged $\mathrm{Fe}_{3} \mathrm{O}_{4} / \mathrm{SiO}_{2}$ nanocomposite particles and positively charged P(S-NIPAM-MMA-PEGMA) hydrogel particles. The morphology, size and size distribution, surface structure, swelling phenomena of two different composite hydrogel particles were characterized. The absorption behavior of biomolecules were also studied and compared.

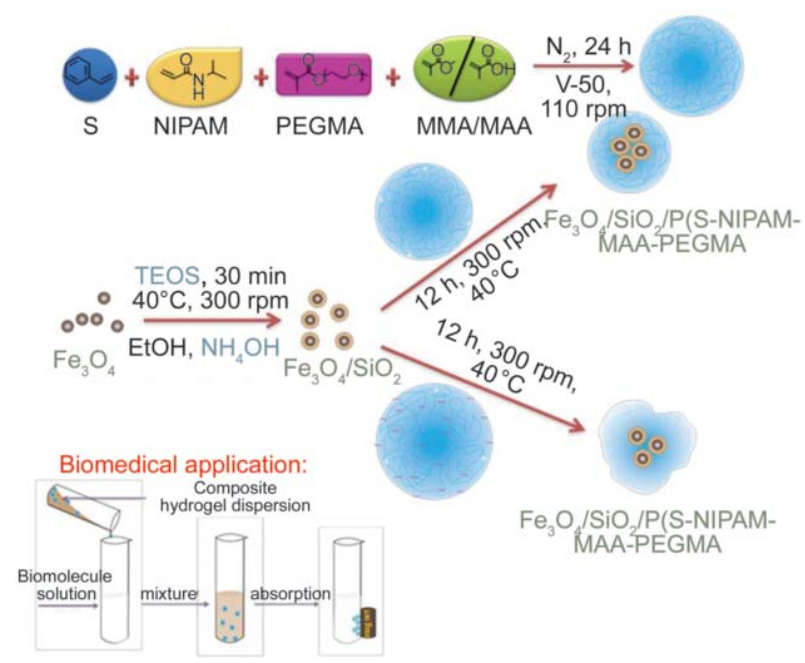

Figure 1. Preparation scheme of magnetic and stimuli-responsive composite hydrogel particles by blending

\section{Experimental section}

\subsection{Materials and instruments}

NIPAM of monomer grade obtained from Across Organics, USA, was recrystallized from a mixture of $90 \%$ hexane and $10 \%$ acetone, dried under vacuum at a low temperature before preserving in the refrigerator. Styrene, MMA and MAA of monomer grade obtained from Fluka Chemica, Switzerland, were purified by passing through activated basic alumina. PEGMA (molecular weight $500 \mathrm{~g} \cdot \mathrm{mol}^{-1}$ for PEG) was obtained from Sigma Aldrich, USA. V-50 from LOBA Chem. India, was recrystallized from distilled water and ethanol. The biomolecules, trypsin (TR) from E. Merck, Darmstadt, Germany, and albumin (AL) from Fluka Chemika, Switzerland, were used without any purification. Ferrous sulphate heptahydrate $\left(\mathrm{FeSO}_{4} \cdot 7 \mathrm{H}_{2} \mathrm{O}\right)$, ferric chloride $\left(\mathrm{FeCl}_{3}\right)$, citric acid, $\mathrm{NH}_{4} \mathrm{OH}$ and other chemicals were of analytical grade. Ethanol and deionized water was distilled using a glass (Pyrex) distillation apparatus.

Transmission electron microscope (TEM) (Zeiss EM-912, Omega), Fourier Transform Infrared (FTIR) spectrophotometer (Perkin Elmer, FTIR-100, USA), Centrifuge machine (TG16-WS) from Kokuson Corporation, Tokyo, Japan, NICOMP 380 particle sizer (USA), X-ray photoelectron spectroscopy (XPS) (PHI X-tool, ULVAC-PHI, Japan) and X-ray diffractometer (XRD) (Bruker D8 Advance, Germany) were used for characterization of prepared particles. Microprocessor $\mathrm{pH}$ meter from HANNA instruments and Sherwood Scientific Magnetic Susceptibility Balance were also used.

\subsection{Preparation of hydrogel particles}

Temperature- and $\mathrm{pH}$-responsive P(S-NIPAM-MAAPEGMA) hydrogel particles were prepared by freeradical precipitation copolymerization from $0.6 \mathrm{~g}$ styrene, $1.95 \mathrm{~g}$ NIPAM, $0.3 \mathrm{~g}$ MAA and $0.15 \mathrm{~g}$ PEGMA. The copolymerization reaction was carried out in a three necked round bottomed flask dipped in thermostat water bath maintained at $75^{\circ} \mathrm{C}$ using cationic V-50 $(0.045 \mathrm{~g})$ initiator. Distilled water $(200 \mathrm{~g})$ was used as the dispersion medium. Polymerization was carried out under a nitrogen atmosphere and the reaction mixture was mechanically stirred at $110 \mathrm{rpm}$ for $24 \mathrm{~h}$.

Compared to this a slightly different recipe was used to prepare stable emulsion of temperature-responsive 
P(S-NIPAM-MMA-PEGMA) hydrogel. This was prepared by free-radical precipitation copolymerization of styrene $(0.75 \mathrm{~g})$, NIPAM (2.04 g), MMA $(0.15 \mathrm{~g})$ and PEGMA $(0.06 \mathrm{~g})$ in a three necked round flask dipped in thermostat water bath at $70^{\circ} \mathrm{C}$. The copolymerization reaction was started using cationic V-50 (0.06 g) initiator in $100 \mathrm{~g}$ distilled water as the dispersion medium. The reaction mixture was mechanically stirred at $110 \mathrm{rpm}$ for $24 \mathrm{~h}$ under a nitrogen atmosphere.

In both cases the conversion was nearly $100 \%$ measured gravimetrically. The hydrogel emulsion was repeatedly washed with distilled water by centrifugation prior to the characterization.

\subsection{Preparation of $\mathrm{Fe}_{3} \mathrm{O}_{4}$ nanoparticles}

Nano-sized $\mathrm{Fe}_{3} \mathrm{O}_{4}$ particles were prepared by co-precipitation of $\mathrm{Fe}^{2+}(2.855 \mathrm{~g})$ and $\mathrm{Fe}^{3+}(3.127 \mathrm{~g})$ from their aqueous solutions (molar ratio 1:2) containing $25 \% 54.05 \mathrm{~g} \mathrm{NH}_{4} \mathrm{OH}$. The reaction was carried out in a three necked round flask under a nitrogen atmosphere for $2 \mathrm{~h}$. The prepared $\mathrm{Fe}_{3} \mathrm{O}_{4}$ emulsion was treated with $10 \mathrm{~g} \mathrm{HNO}_{3}(2 \mathrm{M})$ for $15 \mathrm{~min}$. and washed with water until the solution was neutral. Citric acid (40 g) was added slowly and stirred overnight to stabilize the $\mathrm{Fe}_{3} \mathrm{O}_{4}$ dispersion. The produced $\mathrm{Fe}_{3} \mathrm{O}_{4}$ particles were repeatedly washed by magnetic separation and subsequent redispersion in deionized distilled water to remove salt and excess stabilizer.

\subsection{Preparation of reference $\mathrm{Fe}_{3} \mathrm{O}_{4} / \mathrm{SiO}_{2}$ nanocomposite particles}

At first $50 \mathrm{~g}$ ethanol, $1.0 \mathrm{~g}$ deionized water and $2.38 \mathrm{~g}$ $\mathrm{NH}_{4} \mathrm{OH}$ were taken in a three necked flask under vigorous stirring, then $1.56 \mathrm{~g}$ TEOS was charged into the above mixture and the flask was heated to $40^{\circ} \mathrm{C}$ gradually in a hot water bath with constant stirring at $300 \mathrm{rpm} .20 \mathrm{~min}$ later water-based $0.44 \mathrm{~g}$ magnetic $\left(\mathrm{Fe}_{3} \mathrm{O}_{4}\right)$ fluid containing $0.025 \mathrm{~g}$ solid was added into the above mixture and the process was continued for $30 \mathrm{~min} . \mathrm{Fe}_{3} \mathrm{O}_{4}$ nanoparticles were encapsulated within the $\mathrm{SiO}_{2}$ layer, forming $\mathrm{Fe}_{3} \mathrm{O}_{4} / \mathrm{SiO}_{2}$ nanocomposite particles. The produced particles were washed repeatedly through magnetic separation and redispersion in fresh distilled water before characterization.

\subsection{Preparation of composite hydrogel particles}

$\mathrm{Fe}_{3} \mathrm{O}_{4} / \mathrm{SiO}_{2}$ nanocomposite emulsion was prepared as discussed in the previous section. Calculated amount of hydrogel emulsion (nanocomposite/hydrogel: $1 / 10 \mathrm{w} / \mathrm{w}$ ) was added and the mixture was stirred continuously at $40^{\circ} \mathrm{C}$ for $12 \mathrm{~h}$. The composite hydrogel particles were washed repeatedly by distilled water employing centrifugation followed by magnetic separation to remove any nonmagnetic hydrogel particles.

\subsection{Characterization}

The sample for TEM was prepared by diluting the respective emulsion down to about $0.01 \%$ solid by distilled water and a drop was placed on a carboncoated copper grid. The sample was dried at ambient temperature before observation by an electron microscope at an accelerating voltage of $100 \mathrm{kV}$. FTIR analysis of the powder samples was performed in $\mathrm{KBr}$ pellets and scanned over the range 4000 $400 \mathrm{~cm}^{-1}$ in the deflection mode. Prior to the analysis the washed emulsion was dried under vacuum at low temperature.

The surface composition after modification was evaluated by an XPS equipped with a monochromatic $\mathrm{Al}$ $\mathrm{K} \alpha$ radiation $(1486.6 \mathrm{eV})$ at $104 \mathrm{~W}$ and $20 \mathrm{kV}$ and an X-ray current of $20 \mu \mathrm{A}$. The pressure in the measurement chamber was ca. $8.0 \cdot 10^{-7} \mathrm{~Pa}$. The step size was $0.25 \mathrm{eV}$ for the both survey and high resolution spectra (pass energy $280 \mathrm{eV}$ ). The washed dispersion was dried onto carbon tape prior to the analyses.

The XRD patterns of the powder samples were taken with a scanning XRD using $\mathrm{Cu} \mathrm{K} \alpha$ radiation $(\lambda \approx$ $1.5406 \AA$ ), a tube voltage of $33 \mathrm{kV}$ and a tube current of $45 \mathrm{~mA}$. The intensities were measured at $2 \theta$ values from 2 to $90^{\circ}$ at a continuous scan rate of $10^{\circ} \cdot \mathrm{min}^{-1}$ with a position-sensitive detector aperture at $3^{\circ}$ (equivalent to $0.5^{\circ} \cdot \mathrm{min}^{-1}$ with a scintillation counter).

Thermogravimetric properties (TGA) of the dry powdered samples were measured by heating samples under flowing nitrogen atmosphere from 30 to $600^{\circ} \mathrm{C}$ at a heating rate of $30^{\circ} \mathrm{C} / \mathrm{min}$ and the mass loss was recorded. The initial mass of each sample was around $20 \mathrm{mg}$. 
For the measurement of average hydrodynamic diameters the washed composite/hydrogel dispersion was diluted down to around $0.01 \%$ solid content using water. The $\mathrm{pH}$ value of the diluted emulsion was adjusted whenever necessary. At each temperature the intensity weighted average hydrodynamic diameter of the particles was recorded. Each measurement was carried out in twice and the average value is reported. The reproducibility of the size measurement was within $\pm 5 \%$.

Sherwood Magnetic Susceptibility Balance was used for susceptibility measurement of $\mathrm{Fe}_{3} \mathrm{O}_{4}, \mathrm{Fe}_{3} \mathrm{O}_{4} / \mathrm{SiO}_{2}$ nanocomposite, $\mathrm{Fe}_{3} \mathrm{O}_{4} / \mathrm{SiO}_{2} / \mathrm{P}(\mathrm{S}-\mathrm{NIPAM}-\mathrm{MAA}$ PEGMA) and $\mathrm{Fe}_{3} \mathrm{O}_{4} / \mathrm{SiO}_{2} / \mathrm{P}$ (S-NIPAM-MMAPEGMA) composite hydrogel particles. The particles were separated from their respective dispersion by using a magnet and dried in oven at $70^{\circ} \mathrm{C}$ for several hours. The dried powders were placed in a preweighed sample tube and measured the magnetic susceptibility $\left(\chi_{\mathrm{g}}\right)$ using Equation (1):

$\chi_{\mathrm{g}}=\frac{C \cdot L \cdot\left(R-R_{0}\right)}{m \cdot 10^{9}}$

where $C$, is calibration constant of balance, $L$ is length of the sample in [cm], $R_{0}$ and $R$ are the readings of the empty and sample tubes and $m$ is the weight of sample in $[\mathrm{g}]$.

\subsection{Absorption of biomolecules}

A mixture of $20 \mathrm{~mL}$ was prepared from each purified emulsion containing $0.1 \mathrm{~g}$ solid and biomolecule (200 mg/g) aqueous solution. The $\mathrm{pH}$ value of the emulsion-biomolecule mixture was adjusted at the respective isoelectric point (TR, $\mathrm{pH} 10.0 ; \mathrm{AL}, \mathrm{pH} 6.0$ ) using buffer solution and the mixture was allowed to stand for $45 \mathrm{~min}$. Then the particles were separated magnetically and finally by centrifugation to remove any wafting particles. This same procedure was carried out at two different temperatures of 20 and $40^{\circ} \mathrm{C}$. The concentration of the biomolecule in the supernatant was measured by a UV-visible spectrophotometer at the wave length of $280 \mathrm{~nm}$. The amount of biomolecule absorbed was calculated by subtracting the concentration of free biomolecule from initial concentration. A calibration curve was used for this purpose.

\section{Results and discussion}

Figure 2 represents the TEM images of $\mathrm{Fe}_{3} \mathrm{O}_{4}$, $\mathrm{Fe}_{3} \mathrm{O}_{4} / \mathrm{SiO}_{2}$ nanocomposite, P(S-NIPAM-MAAPEGMA) hydrogel and $\mathrm{Fe}_{3} \mathrm{O}_{4} / \mathrm{SiO}_{2} / \mathrm{P}(\mathrm{S}-\mathrm{NIPAM}-$ MAA-PEGMA) composite hydrogel particles. The average diameters and coefficients of variation $(\mathrm{CV})$ calculated from TEM images are $8.8 \mathrm{~nm}$ and $14.48 \%$ for $\mathrm{Fe}_{3} \mathrm{O}_{4}$ nanoparticles, $28.9 \mathrm{~nm}$ and $10.19 \%$ for $\mathrm{Fe}_{3} \mathrm{O}_{4} / \mathrm{SiO}_{2}$ nanocomposite particles, $590.8 \mathrm{~nm}$ and $36 \%$ for P(S-NIPAM-MAA-PEGMA) hydrogel particles and $49.44 \mathrm{~nm}$ and $12.99 \%$ for $\mathrm{Fe}_{3} \mathrm{O}_{4} / \mathrm{SiO}_{2} / \mathrm{P}(\mathrm{S}$ NIPAM-MAA-PEGMA) composite hydrogel particles. The average size of the $\mathrm{Fe}_{3} \mathrm{O}_{4} / \mathrm{SiO}_{2}$ nanocomposite particles increases after encapsulation with $\mathrm{SiO}_{2}$ layer. It is worth to mention that $\mathrm{Fe}_{3} \mathrm{O}_{4} / \mathrm{SiO}_{2}$ nanocomposite particles undergo drying mediated self assembly into linear chain structure rarely observed in case of magnetic nanoparticles as shown in inset image [65]. P(S-NIPAM-MAA-PEGMA) hydrogel particles exhibit different morphology with central darker parts possibly represents the hydrophobic PS rich segment. The hydrophobic-hydrophobic interactions among PS segments in amphiphilic P(SNIPAM-MAA-PEGMA) conetwork led to the reorientation of polymer chains forming core-shell type microgels in water [60-64]. Compared to P(S-NIPAMMAA-PEGMA) hydrogel particles the size of $\mathrm{Fe}_{3} \mathrm{O}_{4} /$ $\mathrm{SiO}_{2} / \mathrm{P}$ (S-NIPAM-MAA-PEGMA) composite hydrogel particles decreases after blending with $\mathrm{Fe}_{3} \mathrm{O}_{4} /$ $\mathrm{SiO}_{2}$ nanocomposite particles. The blending was carried out under highly alkaline condition $(\sim \mathrm{pH}>10)$. Okubo and coworkers $[66,67]$ proposed the formation mechanism of microparticles from P(S-MAA) copolymer particles dispersed in alkaline solution by simple dissolution method. In case of P(S-NIPAM-MAAPEGMA) hydrogel particles the ionization of carboxyl groups of PMAA under alkaline condition and subsequent swelling and dissolution of copolymer chains from polymer hydrogel particle may take place. It is also possible that hydrophilic soft P(S-NIPAMMAA-PEGMA) hydrogel particles collapsed while the sample was dried during sample preparation for TEM and might not represent the true size of the hydrogel particles as shown in Figure 2c. The presence of negative charges on both $\mathrm{Fe}_{3} \mathrm{O}_{4} / \mathrm{SiO}_{2}$ nanocomposite and P(S-NIPAM-MAA-PEGMA) hydrogel 

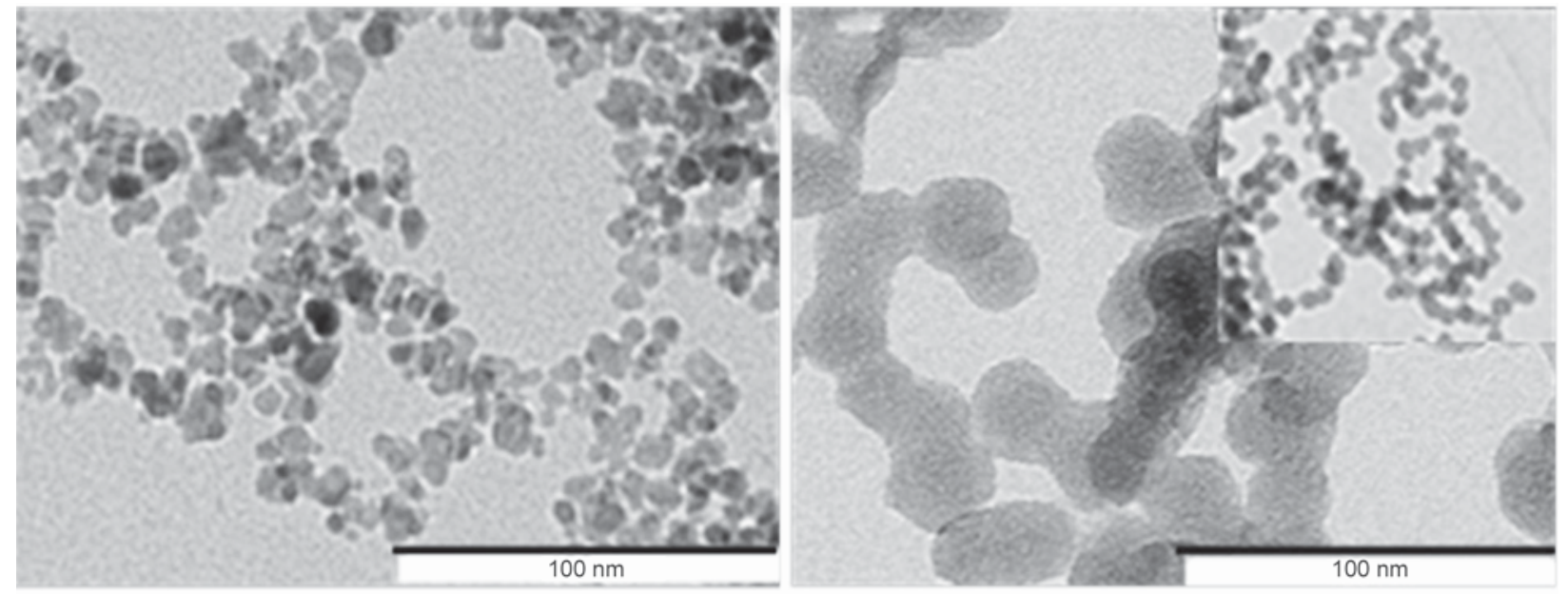

a)

b)
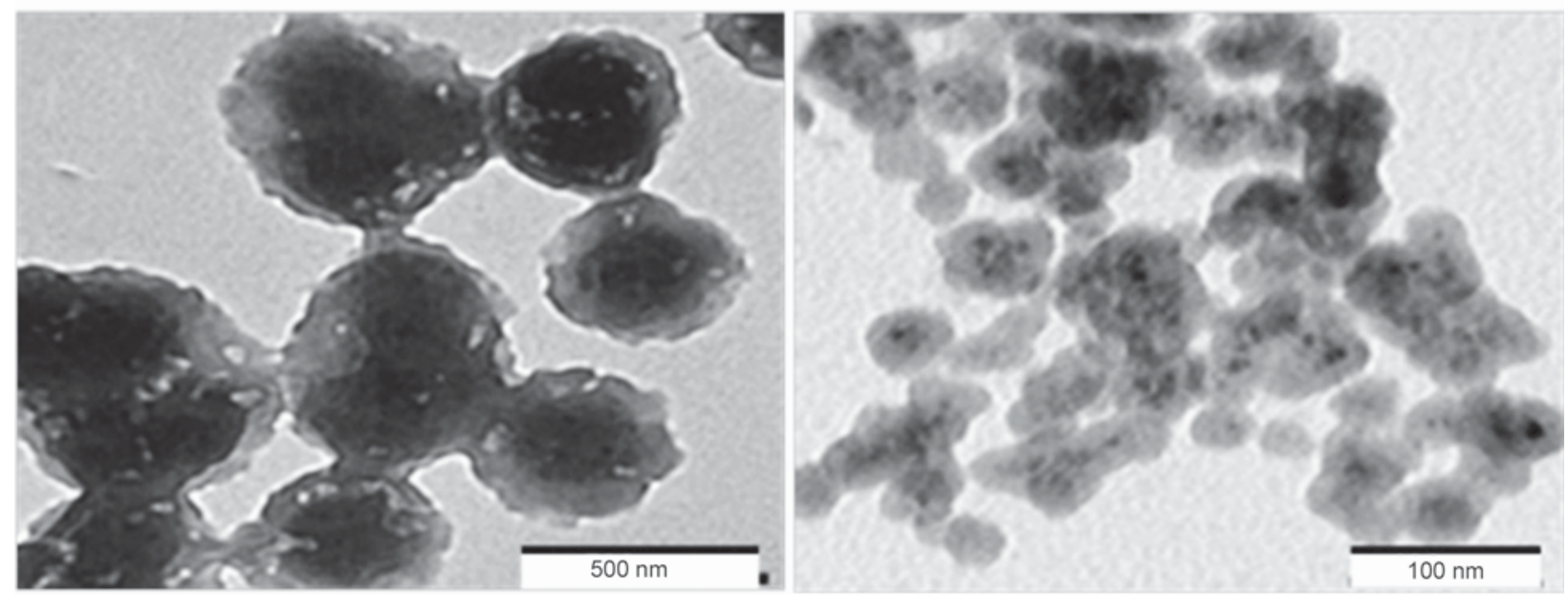

Figure 2. TEM images of a) $\mathrm{Fe}_{3} \mathrm{O}_{4}$, b) $\mathrm{Fe}_{3} \mathrm{O}_{4} / \mathrm{SiO}_{2}$ nanocomposite, c) $\mathrm{P}\left(\mathrm{S}-\mathrm{NIPAM}-\mathrm{MAA}-\mathrm{PEGMA}\right.$ ) hydrogel and d) $\mathrm{Fe}_{3} \mathrm{O}_{4} /$ $\mathrm{SiO}_{2} / \mathrm{P}(\mathrm{S}-\mathrm{NIPAM}-\mathrm{MAA}-\mathrm{PEGMA})$ composite hydrogel particles

particles is also expected to reduce the degree of agglomeration though the later also contain additional positive charges from initiator fragments. These above factors may contribute to the reduction in composite particle size. It is apparent that the morphology of $\mathrm{Fe}_{3} \mathrm{O}_{4} / \mathrm{SiO}_{2} / \mathrm{P}(\mathrm{S}-\mathrm{NIPAM}-\mathrm{MAA}-\mathrm{PEGMA})$ composite hydrogel particles is different from both $\mathrm{P}(\mathrm{S}-\mathrm{NIPAM}-$ MAA-PEGMA) hydrogel particles and $\mathrm{Fe}_{3} \mathrm{O}_{4} / \mathrm{SiO}_{2}$ nanocomposite particles and the average size is larger than those of $\mathrm{Fe}_{3} \mathrm{O}_{4} / \mathrm{SiO}_{2}$ nanocomposite. The tiny nanoparticles inside $\mathrm{Fe}_{3} \mathrm{O}_{4} / \mathrm{SiO}_{2} / \mathrm{P}$ (S-NIPAM-MAAPEGMA) composite hydrogel particles may correspond to $\mathrm{Fe}_{3} \mathrm{O}_{4}$. TEM image of P(S-NIPAM-MMAPEGMA) hydrogel particles shown in Figure 3 suggest that hydrogel particles deformed and possibly collapsed as PMMA is weak to electron beam [68, 69]. Compared to these P(S-NIPAM-MMA-PEGMA) hydrogel particles, $\mathrm{Fe}_{3} \mathrm{O}_{4} / \mathrm{SiO}_{2} / \mathrm{P}(\mathrm{S}-\mathrm{NIPAM}-\mathrm{MMA}$ PEGMA) composite hydrogel particles are rather spherical. The average diameter and coefficient of variation of $\mathrm{Fe}_{3} \mathrm{O}_{4} / \mathrm{SiO}_{2} / \mathrm{P}$ (S-NIPAM-MMA-PEGMA) composite hydrogel particles are $43.43 \mathrm{~nm}$ and $10.19 \%$ and the average size is greater than that of $\mathrm{Fe}_{3} \mathrm{O}_{4} / \mathrm{SiO}_{2}$ nanocomposite particles. The darker central spot may correspond to $\mathrm{Fe}_{3} \mathrm{O}_{4} / \mathrm{SiO}_{2}$ nanocomposite particles as shown in the magnified particle image. These above results suggest that during blending the electrostatic interaction among nanosized $\mathrm{Fe}_{3} \mathrm{O}_{4} / \mathrm{SiO}_{2}$ particles and comparatively softer and larger hydrogel particles initiated the formation of magnetic composite hydrogel particles. The size distribution, nature of charge and charge distribution, particle rigidity, degree of swelling and difference in hydrophilicity all played a role in the formation of nearly core-shell morphology with $\mathrm{Fe}_{3} \mathrm{O}_{4} / \mathrm{SiO}_{2}$ core. FTIR spectral analysis is one way to detect surface structural composition of inorganic and/polymer colloidal particles (Figure 4). In the spectrum of $\mathrm{Fe}_{3} \mathrm{O}_{4}$ 


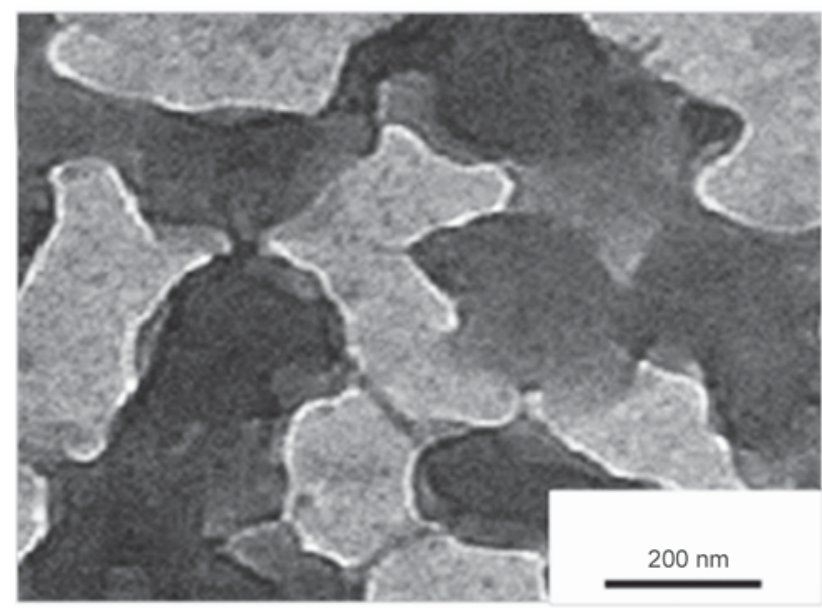

a)

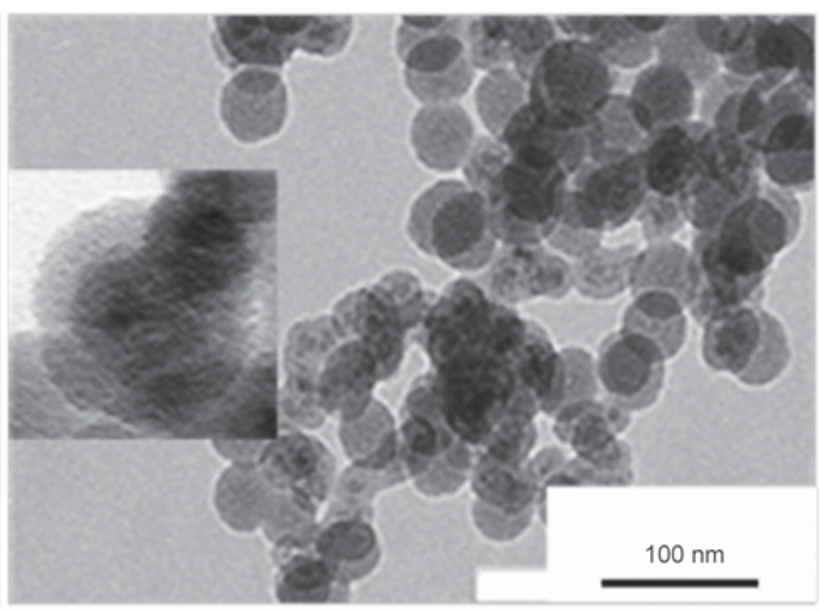

b)

Figure 3. TEM photographs of a) $\mathrm{P}\left(\mathrm{S}-\mathrm{NIPAM}-\mathrm{MMA}-\mathrm{PEGMA}\right.$ ) hydrogel and b) $\mathrm{Fe}_{3} \mathrm{O}_{4} / \mathrm{SiO}_{2} / \mathrm{P}(\mathrm{S}-\mathrm{NIPAM}-\mathrm{MMA}-\mathrm{PEGMA})$ composite hydrogel particles

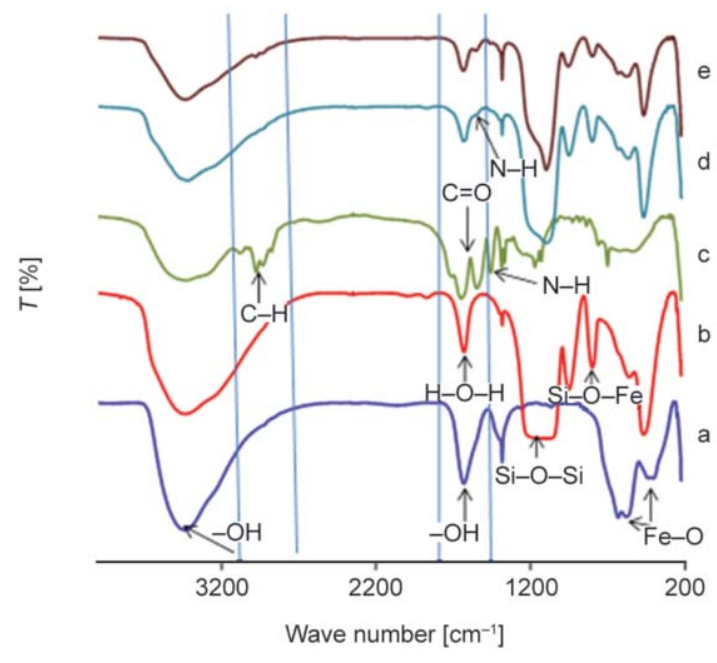

Figure 4. FTIR spectra of a) $\mathrm{Fe}_{3} \mathrm{O}_{4}$, b) $\mathrm{Fe}_{3} \mathrm{O}_{4} / \mathrm{SiO}_{2}$ nanocomposite, c) P(S-NIPAM-MAA-PEGMA) hydrogel, d) $\mathrm{Fe}_{3} \mathrm{O}_{4} / \mathrm{SiO}_{2} / \mathrm{P}(\mathrm{S}-\mathrm{NIPAM}-\mathrm{MAA}-\mathrm{PEGMA})$ and e) $\mathrm{Fe}_{3} \mathrm{O}_{4} / \mathrm{SiO}_{2} / \mathrm{P}$ (S-NIPAM-MMA-PEGMA) composite hydrogel particles recorded in $\mathrm{KBr}$ pellets

nanoparticles (Figure 4 curve a) the intense broad band at $3435.93 \mathrm{~cm}^{-1}$ represents the presence of water traces and non-dissociated-OH groups of citric acid. At $1630.95 \mathrm{~cm}^{-1}$, an intense band is visible which corresponds to the symmetric stretching of $-\mathrm{OH}$ from $-\mathrm{COOH}$ group, revealing the binding of a citric acid radical to the magnetic surface. Also the neighbor band at $1385 \mathrm{~cm}^{-1}$ can be assigned to the asymmetric stretching of $\mathrm{CO}$ from $-\mathrm{COOH}$ group. The characteristic stretching vibrations due to $\mathrm{Fe}-\mathrm{O}$ bonds appear at 406 and $583 \mathrm{~cm}^{-1}$ weakened in $\mathrm{Fe}_{3} \mathrm{O}_{4} /$ $\mathrm{SiO}_{2}$ nanocomposite particles. The weak absorption signal at $800 \mathrm{~cm}^{-1}$ and intense band at $1105 \mathrm{~cm}^{-1}$ in the spectrum of $\mathrm{Fe}_{3} \mathrm{O}_{4} / \mathrm{SiO}_{2}$ nanocomposite particles corresponding to $\mathrm{Si}-\mathrm{O}-\mathrm{Fe}$ and $\mathrm{Si}-\mathrm{O}-\mathrm{Si}$ bonds suggest the bonding of $\mathrm{SiO}_{2}$ to $\mathrm{Fe}_{3} \mathrm{O}_{4}$. In P(S-NIPAMMAA-PEGMA) hydrogel particles the characteristic signals due to stretching vibrations of carboxyl and amide $\mathrm{C}=\mathrm{O}$ groups and amide $\mathrm{N}-\mathrm{H}$ bending appear at 1738,1670 and $1566 \mathrm{~cm}^{-1}$ respectively. Compared to P(S-NIPAM-MAA-PEGMA) hydrogel particles a small but distinct $\mathrm{N}-\mathrm{H}$ bending signal of amide group appears in $\mathrm{Fe}_{3} \mathrm{O}_{4} / \mathrm{SiO}_{2} / \mathrm{P}$ (S-NIPAM-MAA-PEGMA) composite hydrogel particles. The broad absorption signal at $1671-1528 \mathrm{~cm}^{-1}$ due to $\mathrm{H}-\mathrm{O}-\mathrm{H}$ bending in $\mathrm{Fe}_{3} \mathrm{O}_{4} / \mathrm{SiO}_{2}$ nanocomposite particles deviates to 1703-1490 $\mathrm{cm}^{-1}$ in $\mathrm{Fe}_{3} \mathrm{O}_{4} / \mathrm{SiO}_{2} / \mathrm{P}$ (S-NIPAM-MAAPEGMA) composite hydrogel particles. This deviation suggests the inclusion of stretching vibrations of carboxyl and amide $\mathrm{C}=\mathrm{O}$ groups and amide $\mathrm{N}-\mathrm{H}$ bending from copolymer network with the $\mathrm{H}-\mathrm{O}-\mathrm{H}$ bending from $\mathrm{Fe}_{3} \mathrm{O}_{4} / \mathrm{SiO}_{2}$ nanocomposite particles. In other word we can say that bands corresponding to carboxyl and amide $\mathrm{C}=\mathrm{O}$ groups are overlapped with the $\mathrm{H}-\mathrm{O}-\mathrm{H}$ band. Weak $\mathrm{C}-\mathrm{H}$ stretching vibrations of the aliphatic and aromatic ring appear in the region $3085-2798 \mathrm{~cm}^{-1}$. The almost same explanation is also valid for $\mathrm{Fe}_{3} \mathrm{O}_{4} / \mathrm{SiO}_{2} / \mathrm{P}$ (S-NIPAM-MMAPEGMA) composite hydrogel particles.

The XPS C1s, N1s and Fe2p core-line spectra of $\mathrm{Fe}_{3} \mathrm{O}_{4}, \mathrm{Fe}_{3} \mathrm{O}_{4} / \mathrm{SiO}_{2}$ nanocomposite, $\mathrm{Fe}_{3} \mathrm{O}_{4} / \mathrm{SiO}_{2} / \mathrm{P}(\mathrm{S}-$ NIPAM-MAA-PEGMA) and $\mathrm{Fe}_{3} \mathrm{O}_{4} / \mathrm{SiO}_{2} / \mathrm{P}(\mathrm{S}-$ NIPAM-MMA-PEGMA) composite hydrogel particles are shown in Figure 5. The $\mathrm{C} 1 \mathrm{~s}$ signal intensity in $\mathrm{Fe}_{3} \mathrm{O}_{4} / \mathrm{SiO}_{2}$ nanocomposite particles is 5.4 atom $\%$ 

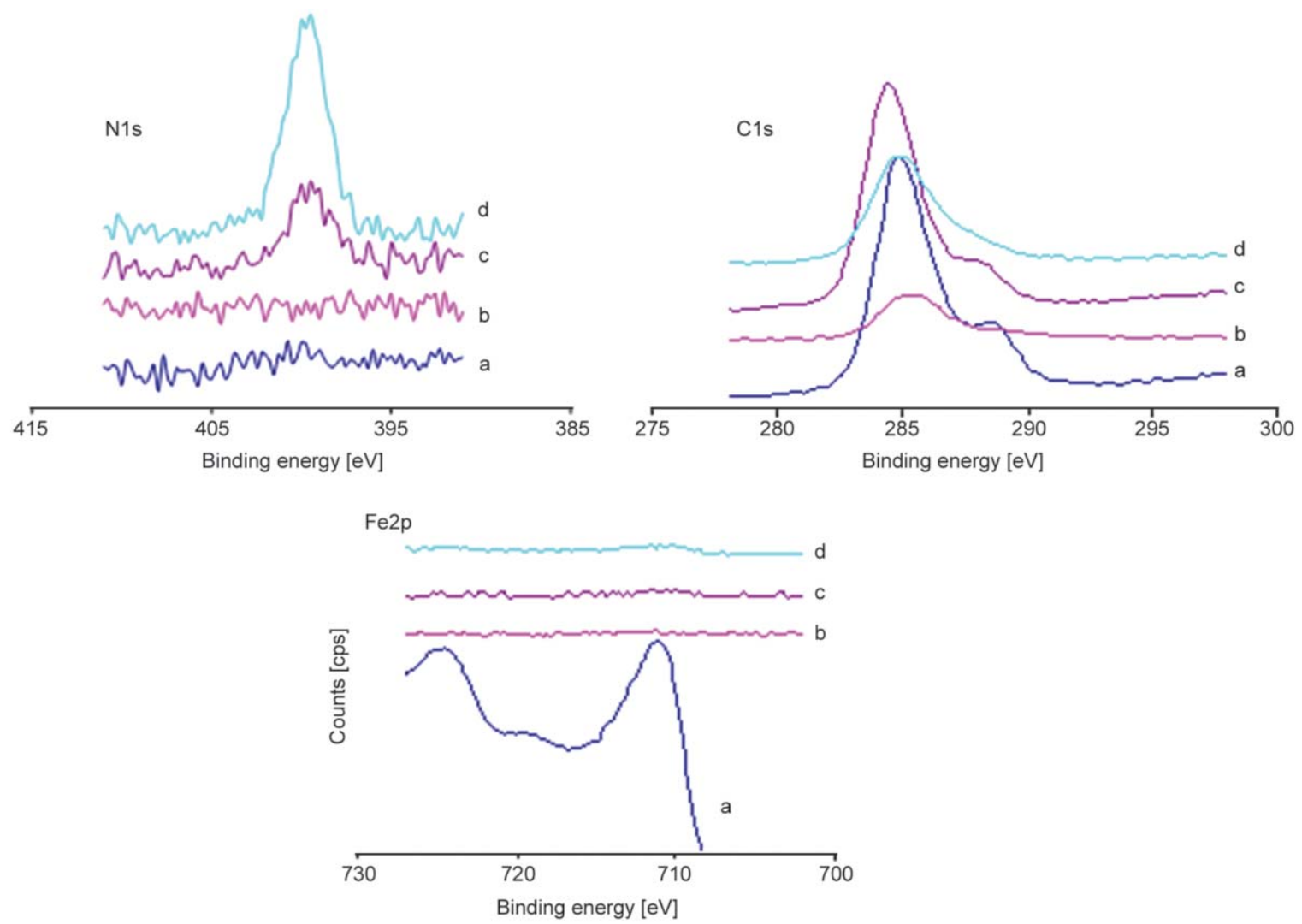

Figure 5. XPS C1s, N1s and Fe2p core-line spectra of curves a) $\mathrm{Fe}_{3} \mathrm{O}_{4}$, b) $\mathrm{Fe}_{3} \mathrm{O}_{4} / \mathrm{SiO}_{2}$ nanocomposite, c) $\mathrm{Fe}_{3} \mathrm{O}_{4} / \mathrm{SiO}_{2} / \mathrm{P}(\mathrm{S}$ NIPAM-MAA-PEGMA) and d) $\mathrm{Fe}_{3} \mathrm{O}_{4} / \mathrm{SiO}_{2} / \mathrm{P}(\mathrm{S}-\mathrm{NIPAM}-M M A-P E G M A)$ composite hydrogel particles

which increases to 29.7 and 14.8 atom $\%$ in $\mathrm{Fe}_{3} \mathrm{O}_{4} /$ $\mathrm{SiO}_{2} / \mathrm{P}$ (S-NIPAM-MAA-PEGMA) and $\mathrm{Fe}_{3} \mathrm{O}_{4} / \mathrm{SiO}_{2} /$ P(S-NIPAM-MMA-PEGMA) composite hydrogel particles. The signal appearance also widened in composite hydrogel particles. The difference in $\mathrm{C} 1 \mathrm{~s}$ signal intensity between $\mathrm{Fe}_{3} \mathrm{O}_{4} / \mathrm{SiO}_{2} / \mathrm{P}$ (S-NIPAM-MAAPEGMA) and $\mathrm{Fe}_{3} \mathrm{O}_{4} / \mathrm{SiO}_{2} / \mathrm{P}$ (S-NIPAM-MMAPEGMA) composite hydrogel particles is attributed to the difference in styrene, MMA and PEGMA contents in the recipe. As expected N1s signal is not visible in $\mathrm{Fe}_{3} \mathrm{O}_{4} / \mathrm{SiO}_{2}$ nanocomposite particles whereas in $\mathrm{Fe}_{3} \mathrm{O}_{4} / \mathrm{SiO}_{2} / \mathrm{P}(\mathrm{S}-\mathrm{NIPAM}-\mathrm{MAA}-\mathrm{PEGMA})$ and $\mathrm{Fe}_{3} \mathrm{O}_{4} / \mathrm{SiO}_{2} / \mathrm{P}$ (S-NIPAM-MMA-PEGMA) composite hydrogel particles such signal intensity approaches 0.8 and 2.2 atom $\%$. The $\mathrm{Fe} 2 \mathrm{p}$ core-line spectrum shown in Figure 5 for $\mathrm{Fe}_{3} \mathrm{O}_{4}$ nanoparticles exhibits two signals at 711.5 and $725.4 \mathrm{eV}$, the characteristic doublets of Fe2 $\mathrm{p}_{3 / 2}$ and $2 \mathrm{p}_{1 / 2}$ core-level spectra of magnetite [70]. The encapsulation by $\mathrm{SiO}_{2}$ followed by polymer layers eliminates the $\mathrm{Fe} 2 \mathrm{p}$ signal. The almost three fold increase in N1s signal intensity derived from PNIPAM segment suggest that specifically the blending of $\mathrm{Fe}_{3} \mathrm{O}_{4} / \mathrm{SiO}_{2}$ nanocomposite and $\mathrm{P}(\mathrm{S}$ NIPAM-MMA-PEGMA) hydrogel particles produces better agglomeration leading to $\mathrm{Fe}_{3} \mathrm{O}_{4} / \mathrm{SiO}_{2} / \mathrm{P}(\mathrm{S}$ NIPAM-MMA-PEGMA) composite hydrogel particles. The ionization of carboxyl group in P(S-NIPAMMAA-PEGMA) hydrogel particles and negative surface charge on $\mathrm{Fe}_{3} \mathrm{O}_{4} / \mathrm{SiO}_{2}$ nanocomposite particles may inhibit the process of agglomeration necessary for composite formation.

The two theta sharp peaks appear at $30.08,35.45$, $43.5,53.54,57.11$ and 62.78 in the XRD spectrum of $\mathrm{Fe}_{3} \mathrm{O}_{4}$ nanoparticles confirm the crystalline cubic spinal structure of $\mathrm{Fe}_{3} \mathrm{O}_{4}$ nanoparticles as shown in Figure 6 . These diffraction peaks are in good agreement with those $\mathrm{XRD}$ patterns of $\mathrm{Fe}_{3} \mathrm{O}_{4}$ nanoparticles reported in the JCPDS-International Center (JCPDS file No. 19-0629) [71, 72]. The broad reflection centers at $\sim 20^{\circ}$ appear in $\mathrm{Fe}_{3} \mathrm{O}_{4} / \mathrm{SiO}_{2}$ nanocomposite particles, $\mathrm{Fe}_{3} \mathrm{O}_{4} / \mathrm{SiO}_{2} / \mathrm{P}(\mathrm{S}-\mathrm{NIPAM}-\mathrm{MAA}-\mathrm{PEGMA})$ and $\mathrm{Fe}_{3} \mathrm{O}_{4} / \mathrm{SiO}_{2} / \mathrm{P}$ (S-NIPAM-MMA-PEGMA) composite hydrogel particles. These broad signals are attributed to the transition of crystalline $\mathrm{Fe}_{3} \mathrm{O}_{4}$ structure into amorphous character following encapsulation by amorphous $\mathrm{SiO}_{2}$ and then polymer layers. The presence of weak characteristic signals of $\mathrm{Fe}_{3} \mathrm{O}_{4}$ in nanocomposite and composite hydrogel particles also con- 


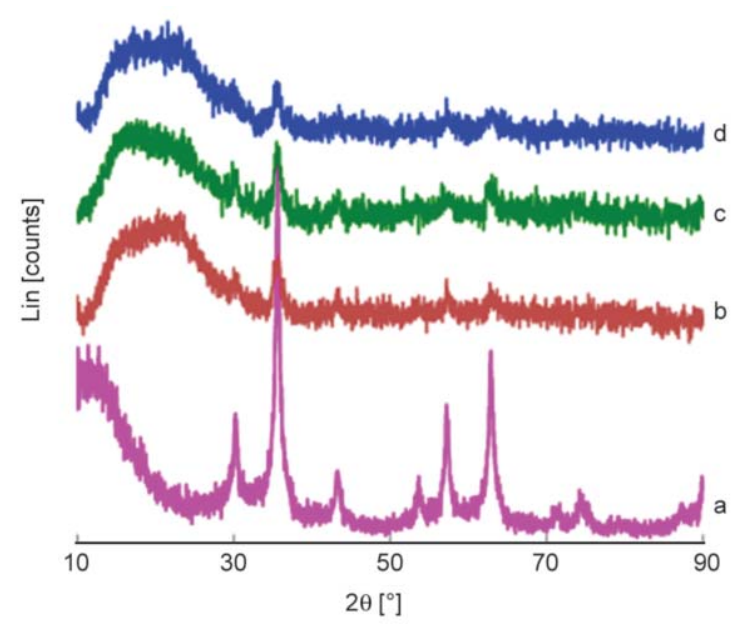

Figure 6. XRD spectra of a) $\mathrm{Fe}_{3} \mathrm{O}_{4}$, b) $\mathrm{Fe}_{3} \mathrm{O}_{4} / \mathrm{SiO}_{2}$ nanocomposite, c) $\mathrm{Fe}_{3} \mathrm{O}_{4} / \mathrm{SiO}_{2} / \mathrm{P}(\mathrm{S}-\mathrm{NIPAM}-\mathrm{MAA}-\mathrm{PEGMA})$ and d) $\mathrm{Fe}_{3} \mathrm{O}_{4} / \mathrm{SiO}_{2} / \mathrm{P}$ (S-NIPAM-MMA-PEGMA) composite hydrogel particles

firms that the crystalline structure of $\mathrm{Fe}_{3} \mathrm{O}_{4}$ is retained during different steps of modification.

The surface modification of $\mathrm{Fe}_{3} \mathrm{O}_{4}$ as well as the presence of inorganic $\left(\mathrm{Fe}_{3} \mathrm{O}_{4} / \mathrm{SiO}_{2}\right)$ part in thermo-responsive composite hydrogel particles can quantified from the percentage of weight loss using TGA curves. It is evident from Figure 7 that both hydrogel particles loss $\sim 98 \%$ of their initial weight. The onset decomposition temperature of P(S-NIPAM-MMAPEGMA) hydrogel particles is slightly high $\left(\sim 329^{\circ} \mathrm{C}\right)$ compared to P(S-NIPAM-MAA-PEGMA) hydrogel particles $\left(\sim 281^{\circ} \mathrm{C}\right)$. Relatively high hydrophobicity and particle rigidity possibly contributed to this higher

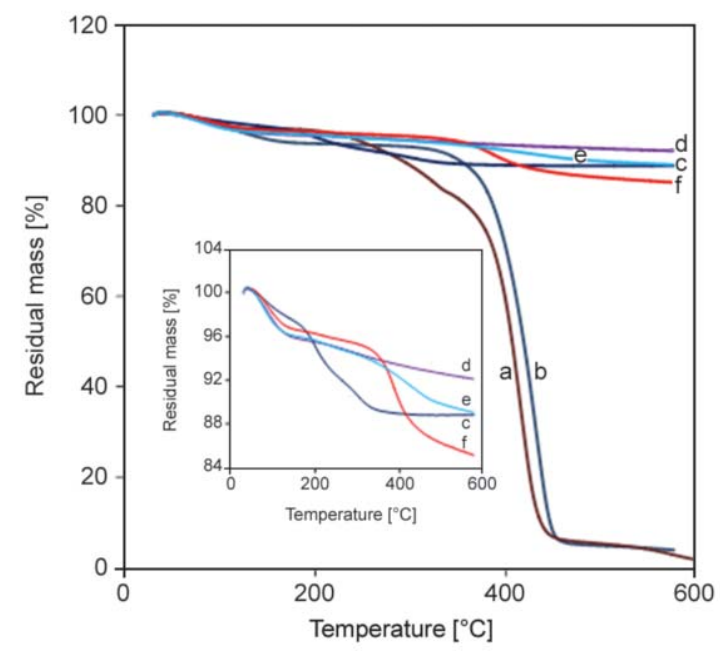

Figure 7. TGA thermograms of a) P(S-NIPAM-MAAPEGMA) hydrogel, b) P(S-NIPAM-MMA-PEGMA) hydrogel, c) $\mathrm{Fe}_{3} \mathrm{O}_{4}$, d) $\mathrm{Fe}_{3} \mathrm{O}_{4} / \mathrm{SiO}_{2}$ nanocomposite, e) $\mathrm{Fe}_{3} \mathrm{O}_{4} / \mathrm{SiO}_{2} / \mathrm{P}(\mathrm{S}-\mathrm{NIPAM}-\mathrm{MAA}-\mathrm{PEGMA})$ and f) $\mathrm{Fe}_{3} \mathrm{O}_{4} / \mathrm{SiO}_{2} / \mathrm{P}(\mathrm{S}-\mathrm{NIPAM}$-MMA-PEGMA) composite hydrogel particles onset decomposition temperature for P(S-NIPAMMMA-PEGMA) hydrogel particles. The incorporation of $\mathrm{SiO}_{2}$ layer in $\mathrm{Fe}_{3} \mathrm{O}_{4}$ reduces the weight loss by $3.5 \%$ indicating the increase in inorganic content. In $\mathrm{Fe}_{3} \mathrm{O}_{4} / \mathrm{SiO}_{2} / \mathrm{P}$ (S-NIPAM-MAA-PEGMA) composite hydrogel particles the weight loss increases by $3.1 \%$ relative to $\mathrm{Fe}_{3} \mathrm{O}_{4} / \mathrm{SiO}_{2}$ nanocomposite particles. Whereas in $\mathrm{Fe}_{3} \mathrm{O}_{4} / \mathrm{SiO}_{2} / \mathrm{P}$ (S-NIPAM-MMA-PEGMA) composite hydrogel particles the weight loss increases by $6.7 \%$ compared to reference $\mathrm{Fe}_{3} \mathrm{O}_{4} / \mathrm{SiO}_{2}$ nanocomposite particles. Overall these results suggest that magnetic composite hydrogel particles are formed in both cases and the use of MMA instead of MAA as a comonomer increases the incorporation of organic polymer. As predicted the ionization of carboxyl group in PMAA under the preparation conditions reduces the extent of agglomeration. The electrostatic repulsion among negatively charged hydrogel particles and negatively charged $\mathrm{Fe}_{3} \mathrm{O}_{4} / \mathrm{SiO}_{2}$ nanocomposite particles may have occurred during blending. It has earlier been mentioned that the negative surface charge on $\mathrm{Fe}_{3} \mathrm{O}_{4} / \mathrm{SiO}_{2}$ nanocomposite particles is derived from the presence of silanol groups. However, based on the recipe the amount of organic part in $\mathrm{Fe}_{3} \mathrm{O}_{4} / \mathrm{SiO}_{2} / \mathrm{P}(\mathrm{S}-\mathrm{NIPAM}-\mathrm{MMA}$-PEGMA) composite hydrogel particles is still low. Under the preparation condition it is reasonable to assume that some hydrogel particles remained free as also observed during washing by magnetic decantation method.

The temperature dependent average hydrodynamic diameters of P(S-NIPAM-MAA-PEGMA) and P(SNIPAM-MMA-PEGMA) hydrogel particles illustrated in Figure 8 show that both hydrogel particles are hydrophilic and swell with water at temperature below the LCST. As the temperature increases the hydrogel particles shrink and deswell at temperature above the LCST. It is apparent that LCST is dependent on the hydrogel composition. The incorporation of hydrophilic PMAA shifts the LCST to relatively higher temperature $\left(37^{\circ} \mathrm{C}\right)$ in P(S-NIPAM-MAAPEGMA) hydrogel particles and the same behavior is also reported elsewhere [73]. The P(S-NIPAMMAA-PEGMA) hydrogel particles also show volume phase transition with respect to variation in $\mathrm{pH}$ value. At higher $\mathrm{pH}$ value the increase in hydrodynamic diameter results from the deprotonation of carboxyl group and hence the coulombic repulsion among polymer chains [74]. 


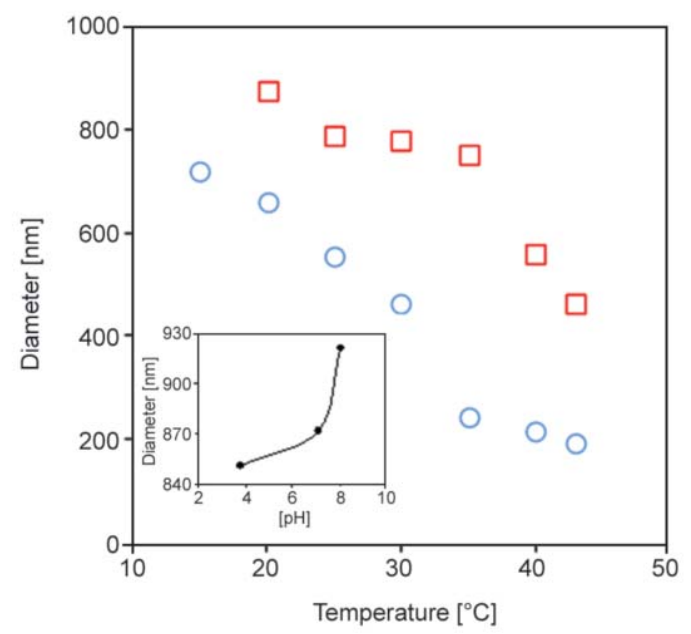

Figure 8. Temperature dependent variations of average hydrodynamic diameters of P(S-NIPAM-MAAPEGMA) (square) and P(S-NIPAM-MMA-PEGMA) (circle) hydrogel particles at $\mathrm{pH}$ 7. $\mathrm{pH}$-dependent variation of average hydrodynamic diameters of P(S-NIPAM-MAA-PEGMA) hydrogel particles at $20^{\circ} \mathrm{C}$ is shown in the inset

The average hydrodynamic diameters of both composite hydrogel particles shown in Figure 9 also decrease with increasing temperature showing LCST behavior. The LCST of $\mathrm{Fe}_{3} \mathrm{O}_{4} / \mathrm{SiO}_{2} / \mathrm{P}$ (S-NIPAMMAA-PEGMA) composite hydrogel particles is relatively high compared to $\mathrm{Fe}_{3} \mathrm{O}_{4} / \mathrm{SiO}_{2} / \mathrm{P}(\mathrm{S}-\mathrm{NIPAM}$ MMA-PEGMA) composite hydrogel particles. Comparatively low hydrodynamic diameter of $\mathrm{Fe}_{3} \mathrm{O}_{4} /$ $\mathrm{SiO}_{2} / \mathrm{P}(\mathrm{S}-\mathrm{NIPAM}-\mathrm{MAA}-\mathrm{PEGMA})$ composite hydrogel microspheres indicate the poor incorporation of polymer hydrogel as predicted in XPS and TGA analyses.

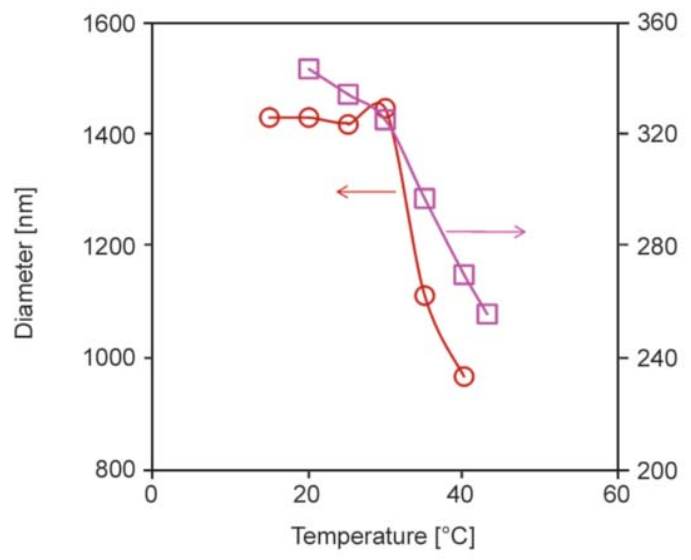

Figure 9. Temperature dependent variations of average hydrodynamic diameters of $\mathrm{Fe}_{3} \mathrm{O}_{4} / \mathrm{SiO}_{2} / \mathrm{P}(\mathrm{S}-\mathrm{NIPAM}$ MAA-PEGMA) (square) and $\mathrm{Fe}_{3} \mathrm{O}_{4} / \mathrm{SiO}_{2} / \mathrm{P}(\mathrm{S}-$ NIPAM-MMA-PEGMA) (circle) composite hydrogel particles measured at $\mathrm{pH} 7$

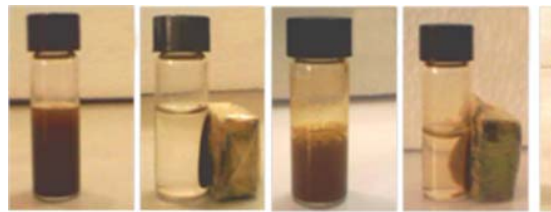

a)

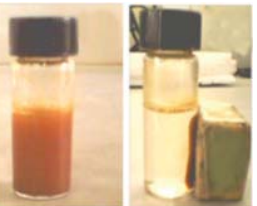

e) f)
Figure 10. Digital photographic images of colloidal dispersions of a, b) $\mathrm{Fe}_{3} \mathrm{O}_{4}$ nanoparticles, c, d) $\mathrm{Fe}_{3} \mathrm{O}_{4} /$ $\mathrm{SiO}_{2} / \mathrm{P}(\mathrm{S}-\mathrm{NIPAM}-\mathrm{MAA}-\mathrm{PEGMA})$ and e, f) $\mathrm{Fe}_{3} \mathrm{O}_{4} /$ $\mathrm{SiO}_{2} / \mathrm{P}(\mathrm{S}-\mathrm{NIPAM}-\mathrm{MMA}-\mathrm{PEGMA}$ ) composite hydrogel particles in absence (a, c, e) and presence $(b, d, f)$ of external magnetic field

The magnetic susceptibilities of $\mathrm{Fe}_{3} \mathrm{O}_{4} / \mathrm{SiO}_{2} / \mathrm{P}(\mathrm{S}$ NIPAM-MAA-PEGMA) and $\mathrm{Fe}_{3} \mathrm{O}_{4} / \mathrm{SiO}_{2} / \mathrm{P}(\mathrm{S}$ NIPAM-MMA-PEGMA) composite hydrogel particles remain high and positive $\left(2.90 \cdot 10^{-3}\right.$ and $\left.1.03 \cdot 10^{-3}\right)$ indicating strong paramagnetic character. The magnetic property is a vital property in separation as well as in targeted drug delivery system because one can drive magnetic particles by applying external magnetic field. Magnetic particles need to be accumulated in presence of magnet and should be well dispersed once the magnet is removed. Figure 10 shows the images of magnetic separation of different magnetic particles. It is observed that the magnetic composite hydrogel particles are well dispersed in absence of magnetic field and accumulated towards the magnet leaving behind almost clear supernatant.

Figures 11 and 12 show the absorption behavior of $\mathrm{TR}$ and $\mathrm{AL}$ on reference $\mathrm{Fe}_{3} \mathrm{O}_{4} / \mathrm{SiO}_{2}$ nanocomposite and $\mathrm{Fe}_{3} \mathrm{O}_{4} / \mathrm{SiO}_{2} / \mathrm{P}$ (S-NIPAM-MAA-PEGMA) and $\mathrm{Fe}_{3} \mathrm{O}_{4} / \mathrm{SiO}_{2} / \mathrm{P}(\mathrm{S}-\mathrm{NIPAM}-\mathrm{MMA}-\mathrm{PEGMA})$ composite hydrogel particles at temperature above and below the LCST. The absorption behavior of biomolecule is a rather complex phenomena depending on the environment as well as nature of sorbent and biomolecules in terms of flexibility, molecular size, hydrophobicity etc. However, irrespective of nature of biomolecules it is evident that magnitude of absorption on composite polymer particles at temperature above the LCST $\left(40^{\circ} \mathrm{C}\right)$ is higher than that at below the LCST $\left(20^{\circ} \mathrm{C}\right)$. Relative to this on $\mathrm{Fe}_{3} \mathrm{O}_{4} / \mathrm{SiO}_{2}$ nanocomposite particles the magnitude of absorption is pretty low. This higher absorption capacity on magnetic and temperature-responsive composite hydrogel particles correspond to comparatively high hydrophobic character. The slight difference in magnitude of absorption between 20 and $40^{\circ} \mathrm{C}$ on $\mathrm{Fe}_{3} \mathrm{O}_{4} / \mathrm{SiO}_{2}$ nanocomposite particles is possibly due to the tem- 


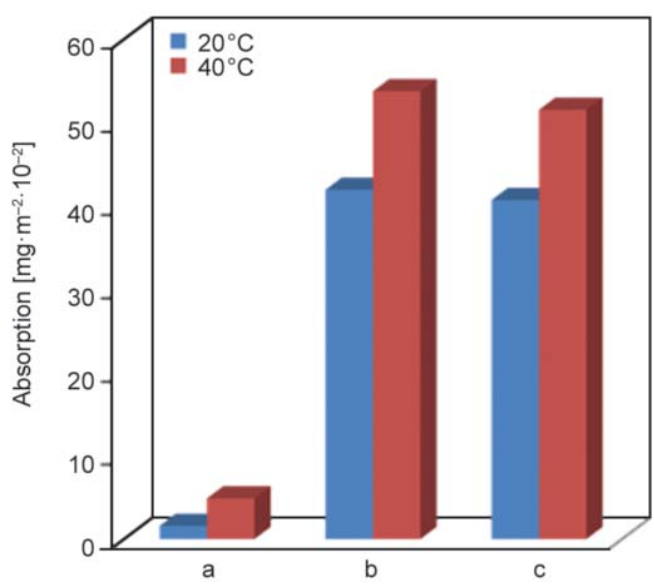

Figure 11. Bar diagram represents the amount of absorptions of trypsin (TR) on a) $\mathrm{Fe}_{3} \mathrm{O}_{4} / \mathrm{SiO}_{2}$ nanocomposite, b) $\mathrm{Fe}_{3} \mathrm{O}_{4} / \mathrm{SiO}_{2} / \mathrm{P}(\mathrm{S}-\mathrm{NIPAM}-\mathrm{MAA}-\mathrm{PEGMA})$ and c) $\mathrm{Fe}_{3} \mathrm{O}_{4} / \mathrm{SiO}_{2} / \mathrm{P}(\mathrm{S}-\mathrm{NIPAM}-\mathrm{MMA}-\mathrm{PEGMA})$ composite hydrogel particles at temperature above $\left(40^{\circ} \mathrm{C}\right)$ and below $\left(20^{\circ} \mathrm{C}\right)$ the LCST. Absorption: immobilization $200 \mathrm{mg} / \mathrm{g}$ of particles, $\mathrm{pH} 10.0$, immobilization time $45 \mathrm{~min}$

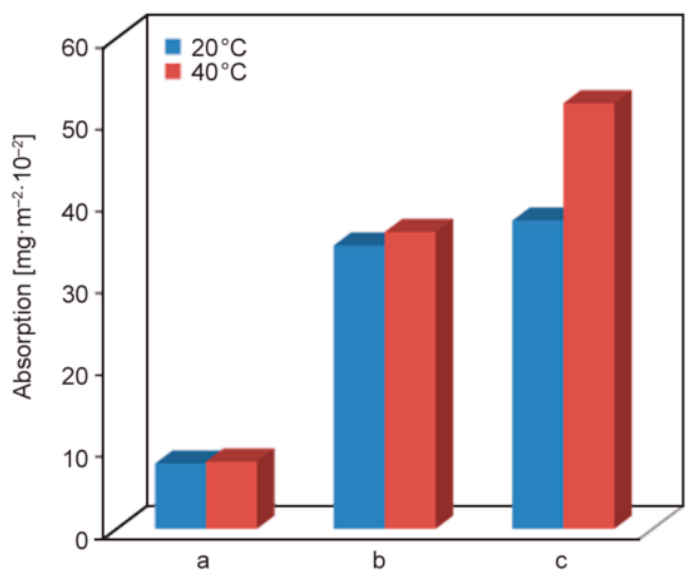

Figure 12. Bar diagram represents the amount of absorptions of albumin (AL) on a) $\mathrm{Fe}_{3} \mathrm{O}_{4} / \mathrm{SiO}_{2}$ nanocomposite, b) $\mathrm{Fe}_{3} \mathrm{O}_{4} / \mathrm{SiO}_{2} / \mathrm{P}$ (S-NIPAM-MAA-PEGMA) and c) $\mathrm{Fe}_{3} \mathrm{O}_{4} / \mathrm{SiO}_{2} / \mathrm{P}(\mathrm{S}-\mathrm{NIPAM}-\mathrm{MMA}-\mathrm{PEGMA})$ composite hydrogel particles at temperature above $\left(40^{\circ} \mathrm{C}\right)$ and below $\left(20^{\circ} \mathrm{C}\right)$ the LCST. Absorption: immobilization $200 \mathrm{mg} / \mathrm{g}$ of particles, $\mathrm{pH}$ 6.0, immobilization time $45 \mathrm{~min}$.

perature effect rather than the surface property of the reference particles.

\section{Conclusions}

Attempt was made to prepare dual temperature- and pH-responsive $\quad \mathrm{Fe}_{3} \mathrm{O}_{4} / \mathrm{SiO}_{2} / \mathrm{P}(\mathrm{S}-\mathrm{NIPAM}-\mathrm{MAA}$ PEGMA) and temperature-responsive $\mathrm{Fe}_{3} \mathrm{O}_{4} / \mathrm{SiO}_{2} / \mathrm{P}(\mathrm{S}$ NIPAM-MMA-PEGMA) composite hydrogel particles by blending $\mathrm{Fe}_{3} \mathrm{O}_{4} / \mathrm{SiO}_{2}$ nanocomposite parti- cles with respective hydrogel particles. It was evident that electrostatic attraction among negatively charged $\mathrm{Fe}_{3} \mathrm{O}_{4} / \mathrm{SiO}_{2}$ nanocomposite particles and positively charged P(S-NIPAM-MMA-PEGMA) hydrogel particles favors the formation of magnetic composite hydrogel particles. Compared to this electrostatic repulsion was dominant when P(S-NIPAMMAA-PEGMA) hydrogel particles were used and produces limited agglomeration. The morphological and chemical structures of magnetic composite particles were evaluated and showed that $\mathrm{Fe}_{3} \mathrm{O}_{4} / \mathrm{SiO}_{2}$ nanocomposite particles are mostly localized at the centre of composite particles with thin copolymer shell layer. The magnetic composite particles exhibited temperature-responsive absorption behavior of biomolecules and can be accumulated towards the external magnetic field.

\section{Acknowledgements}

The author (HA) gratefully acknowledges the partial financial support from the Faculty of Science, Rajshahi University, Bangladesh. The author is also grateful to the Central Science Laboratory, Rajshahi University, for necessary instrument support.

\section{References}

[1] Ha W., Yu J., Song X-Y., Chen J., Shi Y-P.: Tunable temperature-responsive supramolecular hydrogels formed by prodrugs as a codelivery system. ACS Applied Material and Interfaces, 6, 10623-10630 (2014).

DOI: $10.1021 / \mathrm{am} 5022864$

[2] Zhang J., Peppas N. A.: Synthesis and characterization of $\mathrm{pH}$ - and temperature-sensitive poly(methacrylic acid)/ poly $(N$-isopropylacrylamide) interpenetrating polymeric networks. Macromolecules, 33, 102-107 (2000). DOI: $10.1021 / \mathrm{ma991398q}$

[3] Kosik K., Wilk E., Geissler E., László K.: Influence of a crown ether comonomer on the temperature-induced phase transition of poly $(N$-isopropylacrylamide $)$ hydrogels. The Journal of Physical Chemistry B, 112, 10651070 (2008).

DOI: $10.1021 / \mathrm{jp} 075227 \mathrm{~W}$

[4] Gupta M. K., Martin J. R., Werfel T. A., Shen T., Page J. M., Duvall C. L.: Cell protective, ABC triblock polymer-based thermoresponsive hydrogels with ROS-triggered degradation and drug release. Journal of the American Chemical Society, 136, 14896-14902 (2014). DOI: $10.1021 /$ ja507626y

[5] Mu J., Zheng S.: Poly( $N$-isopropylacrylamide) nanocrosslinked by polyhedral oligomeric silsesquioxane: Temperature-responsive behavior of hydrogels. Journal of Colloid and Interface Science, 307, 377-385 (2007). DOI: $10.1016 /$ j.jcis.2006.12.014 
[6] Burek M., Czuba Z. P., Waskiewicz S.: Novel aciddegradable and thermo-sensitive poly $(N$-isopropylacrylamide) hydrogels cross-linked by $\alpha, \alpha$-trehalose diacetals. Polymer, 55, 6460-6470 (2014).

DOI: $10.1016 /$ j.polymer.2014.10.032

[7] Ahmad H., Nurunnabi M., Rahman M. M., Kumar K., Tauer K., Minami H., Gafur M. A.: Magnetically doped multi stimuli-responsive hydrogel microspheres with IPN structure and application in dye removal. Colloids and Surfaces A: Physicochemical and Engineering Aspects, 459, 39-47 (2014).

DOI: $10.1016 /$ j.colsurfa.2014.06.038

[8] Zhang J-T., Jandt K. D.: A novel approach to prepare porous poly( $N$-isopropylacrylamide) hydrogel with superfast shrinking kinetics. Macromolecular Rapid Communications, 29, 593-597 (2008).

DOI: $10.1002 /$ marc. 200700778

[9] Varaprasad K., Ravindra S., Reddy N., Vimala K., Raju K. M.: Design and development of temperature sensitive porous poly(NIPAAm-AMPS) hydrogels for drug release of doxorubicin-A cancer chemotherapy drug. Journal of Applied Polymer Science, 116, 3593-3602 (2010).

DOI: $10.1002 / a p p .31917$

[10] Mishra R. K., Ramasamy K., Majee A. B. A.: pH-responsive poly(DMAPMA-co-HEMA)-based hydrogels for prolonged release of 5-fluorouracil. Journal of Applied Polymer Science, 126, E98-E107 (2012).

DOI: 10.1002/app.36714

[11] Cheng R., Liu J., Xie P., Wu Y., Deng J.: Chiral, pH-sensitive polyacrylamide hydrogels: Preparation and enantio-differentiating release ability. Polymer, 68, 246-252 (2015). DOI: $10.1016 /$ j.polymer.2015.05.034

[12] Longo G. S., de la Cruz M. O., Szleifer I.: Equilibrium adsorption of hexahistidine on $\mathrm{pH}$-responsive hydrogel nanofilms. Langmuir, 30, 15335-15344 (2014). DOI: $10.1021 / 1 \mathrm{a} 5040382$

[13] Shi L., Khondee S., Linz T. H., Berkland C.: Poly(Nvinylformamide) nanogels capable of $\mathrm{pH}$-sensitive protein release. Macromolecules, 41, 6546-6554 (2008). DOI: $10.1021 / \mathrm{ma} 800812 \mathrm{z}$

[14] Suzuki A., Tanaka T.: Phase transition in polymer gels induced by visible light. Nature, 346, 345-347 (1990). DOI: $10.1038 / 346345 \mathrm{a} 0$

[15] Lee M. S., Kim J-C.: Photodependent release from poly(vinyl alcohol)/epoxypropoxy coumarin hydrogels. Journal of Applied Polymer Science, 124, 4339-4345 (2012). DOI: $10.1002 / a p p .35411$

[16] Liu D., Bastiaansen C. W. M., den Toonder J. M. J., Broer D. J.: (Photo-)thermally induced formation of dynamic surface topographies in polymer hydrogel networks. Langmuir, 29, 5622-5629 (2013).

DOI: $10.1021 / 1 \mathrm{a} 4005906$
[17] Yang S., Liu G., Wang X., Song J.: Electroresponsive behavior of a sulfonated poly(vinyl alcohol) hydrogel and its application to electrodriven artificial fish. Journal of Applied Polymer Science, 117, 2346-2353 (2010).

DOI: $10.1002 /$ app.32069

[18] Jin S., Kang H., Huang Y., Liu H., Hu Y.: Synthesis and properties of electrically-sensitive poly(acrylic acid-coacetoacetoxy ethyl methacrylate) gels. Journal of Applied Polymer Science, 110, 3690-3696 (2008). DOI: 10.1002/app.28982

[19] Luo R., Li H., Birgersson E., Lam K. Y.: Modeling of electric-stimulus-responsive hydrogels immersed in different bathing solutions. Journal of Biomedical Materials Research Part A, 85, 248-257 (2008).

DOI: $10.1002 / \mathrm{jbm} . \mathrm{a} .31586$

[20] Li H., Lai F., Luo R.: Analysis of responsive characteristics of ionic-strength-sensitive hydrogel with consideration of effect of equilibrium constant by a chemoelectro-mechanical model. Langmuir, 25, 13142-13150 (2009). DOI: $10.1021 / 1 \mathrm{a901833m}$

[21] Zhao B., Moore J. S.: Fast pH- and ionic strength-responsive hydrogels in microchannels. Langmuir, 17, 4758-4763 (2001).

DOI: $\underline{10.1021 / 1 \mathrm{a} 001709 \mathrm{~m}}$

[22] Rasool N., Yasin T., Heng J. Y. Y., Akhter Z.: Synthesis and characterization of novel $\mathrm{pH}$-, ionic strength and temperature- sensitive hydrogel for insulin delivery. Polymer, 51, 1687-1693 (2010).

DOI: 10.1016/j.polymer.2010.02.013

[23] Hokray F., Basser P. J., Hecht A-M., Geissler E.: Calcium-induced volume transition in polyacrylate hydrogels swollen in physiological salt solutions. Macromolecular Bioscience, 2, 207-213 (2002).

DOI: 10.1002/1616-5195(200206)2:5<207::AIDMABI207>3.0.CO;2-5

[24] Bucatariu S., Fundueanu G., Prisacaru I., Balan M., Stoica I., Harabagiu V., Constantin M.: Synthesis and characterization of thermosensitive poly $(\mathrm{N}$-isopropylacrylamide-co-hydroxyethylacrylamide) microgels as potential carriers for drug delivery. Journal of Polymer Research, 21, 580/1-580/12 (2014).

DOI: $10.1007 / \mathrm{s} 10965-014-0580-7$

[25] Gan T., Guan Y., Zhang Y.: Thermogelable PNIPAM microgel dispersion as 3D cell scaffold: Effect of syneresis. Journal of Materials Chemistry, 20, 59375944 (2010). DOI: $10.1039 / \mathrm{c} 0 \mathrm{jm} 00338 \mathrm{~g}$

[26] Belger C., Weis J. G., Egap E., Swager T. M.: Colorimetric stimuli-responsive hydrogel polymers for the detection of nerve agent surrogates. Macromolecules, $\mathbf{4 8}$, 7990-7994 (2015).

DOI: $10.1021 /$ acs.macromol.5b01406 
[27] Li L., Gu J., Zhang J., Xie Z., Lu Y., Shen L., Dong Q., Wang Y.: Injectable and biodegradable pH-responsive hydrogels for localized and sustained treatment of human fibrosarcoma. ACS Applied Material and Interfaces, 7, 8033-8040 (2015).

DOI: $10.1021 /$ acsami.5b00389

[28] Popescu M-T., Mourtas S., Pampalakis G., Antimisiaris S. G., Tsitsilianis C.: pH-responsive hydrogel/liposome soft nanocomposites for tuning drug release. Biomacromolecules, 12, 3023-3030 (2011).

DOI: $10.1021 / \mathrm{bm} 2006483$

[29] Deng K., Dong L., Li Q., Gou Y., Zhang P., Ren X., Zhong H.: Drug release behaviors of a novel $\mathrm{pH} / \mathrm{tem}$ perature-responsive chitosan-poly ( $\mathrm{N}$-acryloylglycinate $)$ hydrogel. Journal of Applied Polymer Science, 120, 3297-3303 (2011).

DOI: $10.1002 /$ app.33522

[30] Wang X., Qiu X., Wu C.: Comparison of the coil-toglobule and the globule-to-coil transitions of a single poly $(\mathrm{N}$-isopropylacrylamide) homopolymer chain in water. Macromolecules, 31, 2972-2976 (1998).

DOI: $10.1021 / \mathrm{ma} 971873 \mathrm{p}$

[31] Li Y., Guo H., Gan J., Zheng J., Zhang Y., Wu K., Lu M.: Novel fast thermal-responsive poly $(N$-isopropylacrylamide) hydrogels with functional cyclodextrin interpenetrating polymer networks for controlled drug release. Journal of Polymer Research, 22, 91/1-91/14 (2015).

DOI: $10.1007 / \mathrm{s} 10965-015-0720-8$

[32] Alam M. A., Sultana T., Rahman M. A., Nuri M. A., Miah M. A. J., Ahmad H.: Preparation of carboxylated temperature-responsive magnetic nano composite polymer particles. Macromolecules: An Indian Journal, 9, 8590 (2013).

[33] Brazel C. S.: Magnetothermally-responsive nanomaterials: Combining magnetic nanostructures and thermally-sensitive polymers for triggered drug release. Pharmaceutical Research, 26, 644-656 (2008).

DOI: $10.1007 / \mathrm{s} 11095-008-9773-2$

[34] Zhang J. L., Srivastava R. S., Misra R. D. K.: Coreshell magnetite nanoparticles surface encapsulated with smart stimuli-responsive polymer: Synthesis, characterization, and LCST of viable drug-targeting delivery system. Langmuir, 23, 6342-6351 (2007).

DOI: $10.1021 / 1 \mathrm{a} 0636199$

[35] Luo B., Song X-J., Zhang F., Xia A., Yang W-L., Hu JH., Wang C-C.: Multi-functional thermosensitive composite microspheres with high magnetic susceptibility based on magnetite colloidal nanoparticle clusters. Langmuir, 26, 1674-1679 (2010).

DOI: $10.1021 / 1 \mathrm{a} 902635 \mathrm{k}$

[36] Zhang B., Zhang H., Fan X., Li X., Yin D., Zhang Q.: Preparation of thermoresponsive $\mathrm{Fe}_{3} \mathrm{O}_{4} / \mathrm{P}$ (acrylic acidmethyl methacrylate $-N$-isopropylacrylamide) magnetic composite microspheres with controlled shell thickness and its releasing property for phenolphthalein. Journal of Colloid and Interface Science, 398, 51-58 (2013). DOI: $10.1016 /$ j.jcis.2013.01.042
[37] Reddy N. N., Ravindra S., Reddy N. M., Rajinikanth V., Raju K. M., Vallabhapurapu V. S.: Temperature responsive hydrogel magnetic nanocomposites for hyperthermia and metal extraction applications. Journal of Magnetism and Magnetic Materials, 394, 237-244 (2015).

DOI: $10.1016 /$ j.jmmm.2015.06.065

[38] Majewski A. P., Schallon A., Jérôme V., Freitag V. R., Müller A. H. E., Schmalz H.: Dual-responsive magnetic core-shell nanoparticles for nonviral gene delivery and cell separation. Biomacromolecules, 13, 857-866 (2012). DOI: $\underline{10.1021 / \mathrm{bm} 2017756}$

[39] Rahman M. M., Chehimi M. M., Fessi H., Elaissari A.: Highly temperature responsive core-shell magnetic particles: Synthesis, characterization and colloidal properties. Journal of Colloid and Interface Science, 360, 556-564 (2011).

DOI: $\underline{10.1016 / \text { j.jcis.2011.04.078 }}$

[40] Pich A., Bhattacharya S., Lu Y., Boyko V., Adler H-J. P.: Temperature-sensitive hybrid microgels with magnetic properties. Langmuir, 20, 10706-10711 (2004). DOI: $10.1021 / 1 \mathrm{a} 040084 \mathrm{f}$

[41] Dagallier C., Dietsch H., Schurtenberger P., Scheffold F.: Thermoresponsive hybrid microgel particles with intrinsic optical and magnetic anisotropy. Soft Matter, 6, 2174-2177 (2010). DOI: $10.1039 / \mathrm{c} 000305 \mathrm{k}$

[42] Karg M., Pastoriza-Santos I., Liz-Marzán L. M., Hellweg T.: A versatile approach for the preparation of thermosensitive PNIPAM core-shell microgels with nanoparticle cores. ChemPhysChem, 7, 2298-2301 (2006). DOI: $10.1002 / \mathrm{cphc} .200600483$

[43] Shamim N., Hong L., Hidajat K., Uddin M. S.: Thermosensitive-polymer-coated magnetic nanoparticles: Adsorption and desorption of bovine serum albumin. Journal of Colloid and Interface Science, 304, 1-8 (2006). DOI: $10.1016 /$ j.jcis.2006.08.047

[44] Purushotham S., Ramanujan R. V.: Thermoresponsive magnetic composite nanomaterials for multimodal cancer therapy. Acta Biomaterialia, 6, 502-510 (2010). DOI: $10.1016 /$ j.actbio.2009.07.004

[45] Rahman M. M., Elaissari A.: Multi-stimuli responsive magnetic core-shell particles: Synthesis, characterization and specific RNA recognition. Journal of Colloid Science and Biotechnology, 1, 3-15 (2012).

DOI: $10.1166 /$ jesb.2012.1006

[46] Ding X. B., Sun Z. H., Wan G. X., Jiang Y. Y.: Preparation of thermosensitive magnetic particles by dispersion polymerization. Reactive and Functional Polymers, 38, 11-15 (1998). DOI: $10.1016 / \mathrm{S} 1381-5148(97) 00154-5$

[47] Ahmad H., Rahman M. A., Miah M. A. J., Tauer K.: Magnetic and temperature-sensitive composite polymer particles and adsorption behavior of emulsifiers and trypsin. Macromolecular Research, 16, 637-643 (2008). DOI: $10.1007 / \mathrm{BF} 03218573$ 
[48] Liu C., Guo J., Yang W., Hu J., Wang C., Fu S.: Magnetic mesoporous silica microspheres with thermo-sensitive polymer shell for controlled drug release. Journal of Materials Chemistry, 19, 4764-4770 (2009). DOI: $10.1039 / \mathrm{b} 902985 \mathrm{k}$

[49] Baharvand H.: A new method for preparation of magnetic polymer particles. Colloid and Polymer Science, 292, 3311-3318 (2014). DOI: 10.1007/s00396-014-3386-6

[50] Cai J., Guo J., Ji M., Yang W., Wang C., Shoukuan F.: Preparation and characterization of multiresponsive polymer composite microspheres with core-shell structure. Colloid and Polymer Science, 285, 1607-1615 (2007). DOI: 10.1007/s00396-007-1735-4

[51] Guo J., Yang W., Deng Y., Wang C., Fu S.: Organicdye-coupled magnetic nanoparticles encaged inside thermoresponsive PNIPAM microcapsules. Small, 1, 737-743 (2005).

DOI: $10.1002 / \mathrm{smll} .200400145$

[52] Narain R., Gonzales M., Hoffman A. S., Stayton P. S., Krishnan K. M.: Synthesis of monodisperse biotinylated $\mathrm{p}$ (NIPAAm)-coated iron oxide magnetic nanoparticles and their bioconjugation to streptavidin. Langmuir, 23, 6299-6304 (2007).

DOI: $10.1021 / 1 \mathrm{la} 700268 \mathrm{~g}$

[53] Kakwere H., Leal M. P., Materia M. E., Curcio A., Guardia P., Niculaes D., Marotta R., Falqui A., Pellegrino T.: Functionalization of strongly interacting magnetic nanocubes with (thermo)responsive coating and their application in hyperthermia and heat-triggered drug delivery. ACS Applied Material and Interfaces, 7, 10132-10145 (2015).

DOI: $10.1021 / \mathrm{am} 5088117$

[54] Kurzhals S., Zirbs R., Reimhult E.: Synthesis and magneto-thermal actuation of iron oxide core-PNIPAM shell nanoparticles. ACS Applied Materials and Interfaces, 7, 19342-19352 (2015).

DOI: $10.1021 /$ acsami.5b05459

[55] Frimpong R. A., Hilt J. Z.: Poly( $N$-isopropylacrylamide)-based hydrogel coatings on magnetite nanoparticles via atom transfer radical polymerization. Nanotechnology, 19, 175101/1-175101/8 (2008).

DOI: $10.1088 / 0957-4484 / 19 / 17 / 175101$

[56] Binder W. H., Gloger D., Weinstabl H., Allmaier G., Pittenauer E.: Telechelic poly $(N$-isopropylacrylamides $)$ via nitroxide-mediated controlled polymerization and 'click' chemistry: Livingness and 'grafting-from' methodology. Macromolecules, 40, 3097-3107 (2007).

DOI: $10.1021 / \mathrm{ma} 0628376$

[57] Prai-in Y., Tankanya K., Rutnakornpituk B., Wichai U., Montembault V., Pascual S., Fontaine L., Rutnakornpituk M.: Azlactone functionalization of magnetic nanoparticles using ATRP and their bioconjugation. Polymer, 53, 113-120 (2012).

DOI: $10.1016 /$ j.polymer.2011.11.021
[58] Ohno K., Ma Y., Huang Y., Mori C., Yahata Y., Tsujii Y., Maschmeyer T., Moraes J., Perrier S.: Surface-initiated reversible addition-fragmentation chain transfer (RAFT) polymerization from fine particles functionalized with trithiocarbonates. Macromolecules, 44, 89448953 (2011).

DOI: $10.1021 / \mathrm{ma} 202105 \mathrm{y}$

[59] Illés E., Tombácz E., Szekeres M., Tóth I. Y., Szabó Á., Iván B.: Novel carboxylated PEG-coating on magnetite nanoparticles designed for biomedical applications. Journal of Magnetism and Magnetic Materials, 380, 132-139 (2015).

DOI: $10.1016 /$ j.jmmm.2014.10.146

[60] Szabó Á., Wacha A., Thomann R., Szarka G., Bóta A., Iván B.: Synthesis of poly(methyl methacrylate)-poly (poly(ethylene glycol) methacrylate)-polyisobutylene abcba pentablock copolymers by combining quasiliving carbocationic and atom transfer radical polymerizations and characterization thereof. Journal of Macromolecular Science Part A: Pure and Applied Chemistry, 52, 252-259 (2015).

DOI: $10.1080 / 10601325.2015 .1007268$

[61] Kali G., Vavra S., László K., Iván B.: Thermally responsive amphiphilic conetworks and gels based on $\operatorname{poly}(\mathrm{N}$ isopropylacrylamide) and polyisobutylene. Macromolecules, 46, 5337-5344 (2013).

DOI: $10.1021 / \mathrm{ma} 400535 \mathrm{r}$

[62] Kali G., Iván B.: Poly(methacrylic acid)-l-polyisobutylene amphiphilic conetworks by using an ethoxyethylprotected comonomer: Synthesis, protecting group removal in the cross-linked state, and characterization. Macromolecular Chemistry and Physics, 216, 605-613 (2015). DOI: $10.1002 /$ macp. 201400478

[63] Haraszti M., Tóth E., Iván B.: Poly(methacrylic acid)l-polyisobutylene: A novel polyelectrolyte amphiphilic conetwork. Chemistry of Materials, 18, 4952-4958 (2006). DOI: $10.1021 / \mathrm{cm} 061119 \mathrm{v}$

[64] Iván B., Haraszti M., Erdődi G., Scherble J., Thomann R., Mülhaupt R.: New nanophase separated intelligent amphiphilic conetworks and gels. Macromolecular Symposia, 227, 265-274 (2005).

DOI: $10.1002 /$ masy.200550926

[65] Poddar P., Telem-Shafir T., Fried T., Markovich G.: Dipolar interactions in two- and three-dimensional magnetic nanoparticle arrays. Physical Review B, 66, 060403/1060403/4 (2002). DOI: 10.1103/PhysRevB.66.060403

[66] Okubo M., Fukami N., Shinohara R.: Behavior of nonionic emulsifier molecules on the preparation of nanoparticles from submicron-sized ionized styrenemethacrylic acid copolymer particles by the particle dissolution method. Colloid and Polymer Science, 277, 900-904 (1999). DOI: $10.1007 / \mathrm{s} 003960050469$ 
[67] Okubo M., Ichikawa K.: Production of multihollow polymer particles by the stepwise alkali/acid method IV. Acid treatment process. Colloid and Polymer Science, 272, 933-937 (1994).

DOI: $10.1007 / \mathrm{BF} 00658890$

[68] Sawyer L. C., Grubb D. T.: Polymer microscopy. Chapman and Hall, New York (1994).

[69] Ahmad H., Miah M. A. J., Pervin M. S., Rahman M. M.: Composite polymer particles prepared with different amounts of acrylic acid and their usefulness as carriers for biomolecules. Colloid and Polymer Science, 281, 897-901 (2003).

DOI: $10.1007 / \mathrm{s} 00396-002-0856-\mathrm{Z}$

[70] Márquez F., Campo T., Cotto M., Polanco R., Roque R., Fierro P., Sanz J. M., Elizalde E., Morant C.: Synthesis and characterization of monodisperse magnetite hollow microspheres. Soft Nanoscience Letters, 1, 25-32 (2011). DOI: $\underline{10.4236 / \mathrm{snl} .2011 .12005}$
[71] Hui C., Shen C., Yang T., Bao L., Tian J., Ding H., Li C., Gao H-J.: Large-scale $\mathrm{Fe}_{3} \mathrm{O}_{4}$ nanoparticles soluble in water synthesized by a facile method. The Journal of Physical Chemistry C, 112, 11336-11339 (2008). DOI: $10.1021 /$ jp $801632 p$

[72] Salem N. M., Ahmad A. L., Awwad A. M.: New route for synthesis magnetic nanoparticles from ferrous ions and pistachio leaf extract. Nanoscience and Nanotechnology, 3, 48-51 (2013). DOI: $10.5923 / \mathrm{j} . \mathrm{nn} .20130303 .03$

[73] Okubo M., Ahmad H., Komura M.: Preparation of temperature-sensitive polymer particles having different lower critical solution temperatures. Colloid and Polymer Science, 274, 1188-1191 (1996).

DOI: $10.1007 / \mathrm{BF} 00655691$

[74] Alam M. A., Miah M. A. J., Ahmad H.: Synthesis and characterization of dual-responsive micrometer-sized core-shell composite polymer particles. Polymers for Advanced Technologies, 19, 181-185 (2008).

DOI: $10.1002 /$ pat.993 